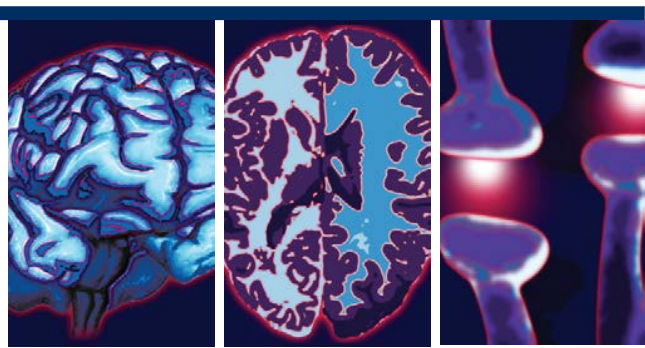

\title{
Implications of Polymorphisms in the CRHR1 Gene on the Hypothalamic-Pituitary-Adrenal Axis Functioning in Postpartum Depression
}

Marcos Gonçalves de Rezende ${ }^{1,5, t}$, Felipe Pinheiro de Figueiredo ${ }^{1,5}$, Cybele Garcia-Leal ${ }^{1,5}$, Helene Aparecida Fachim ${ }^{1,5}$, Marco Antonio Barbieri ${ }^{2,5}$, Heloisa Bettiol ${ }^{2,5}$, Ricardo de Carvalho Cavalli ${ }^{3,5}$, Margaret de Castro ${ }^{4,5}$, Cristina Marta DelBen $^{1,5}$

\section{Abstract}

\section{Objective:}

This study was aimed at assessing the association of the TAT haplotype of the corticotropinreleasing hormone receptor type 1 (CRHR1) with the function of the hypothalamic-pituitaryadrenal (HPA) axis in depressive and euthymic women in the remote postpartum period.

\section{Methods:}

The sample (mean age $=27.9 \pm 5.3$ years) consisted of 37 depressed postpartum women, of which 26 had one or two copies of the TAT haplotype (D-TAT ${ }^{1 / 2}$ ) and 11 had no TAT haplotype (D-TATO), and 41 euthymic postpartum women, being 21 with one or two copies of the TAT haplotype $\left(E-T^{-1 / 2}\right)$ and 20 without the TAT haplotype (E-TAT $\left.{ }^{0}\right)$. Salivary cortisol samples were collected immediately upon awakening and 30 minutes, 3 hours and 12 hours later, approximately in the sixth month after delivery (mean $=169.6 \pm 60.3$ days). DNA for genotyping was extracted between 22 and 25 weeks of pregnancy.

Results: D-TAT $1 / 2$ women presented lower cortisol awakening response (CAR) compared with $\mathrm{E}-\mathrm{TAT}^{1 / 2}$ and E-TAT ${ }^{0}$ women. Independently of the diagnosis of depression, only women with at least one copy of the TAT haplotype presented a negative correlation between CAR and scores of perceived stress during pregnancy and depressive symptoms in the postpartum.

Conclusion: The association between CRHR1 polymorphisms and postpartum depression may be mediated by variability in individual responses to stress as assessed through HPA axis responsiveness.

\section{Keywords:}

Postpartum depression, Cortisol awakening response, Salivary cortisol, HPA axis, crhr1 gene, TAT haplotype, Stress

\section{Introduction}

Postpartum depression (PPD) is a significant cause of morbidity among women [1] and is related to relevant emotional, cognitive and behavioral impairments in the offspring $[2,3]$. Depressive episodes during the postpartum 
period are highly prevalent, affecting 10-15\% of postpartum women in Western Europe and North America, and up to $40 \%$ of postpartum women in developing regions of the globe, which suggests a probable involvement of environmental factors in the occurrence of PPD [4]. Among other factors, the significant hormonal changes that occur during pregnancy and in the immediate postpartum may contribute to an increased sensitivity to environmental stressors and a greater vulnerability to PPD [5]. Indeed, hormonal fluctuations are associated with depressive symptoms in the postpartum $[6,7]$, particularly alterations related to the hypothalamic-pituitary-adrenal (HPA) axis $[8,9]$. Changes in HPA axis function associated with depressive symptoms have been observed in different periods of the postpartum $[10,11]$.

The HPA axis plays a central role in the response to stress and maintenance of homeostasis, with important neurobehavioral consequences and implications in the pathophysiology of depressive and anxiety disorders [12,13]. The HPA axis is under the control of negative feedback mechanisms and circadian variations in the lightdark cycle. During pregnancy, the corticotropinreleasing hormone $(\mathrm{CRH})$, ordinarily produced by the paraventricular nucleus of the hypothalamus (PVN), is also produced by the placenta, leading to a significant increase in the circulating levels of CRH in the mother's blood [14]. The CRH system plays an important role in the coordination of physiological stress responses with different functions and at different brain levels [15]. The CRH type 1 receptor (CRHR1), the main receptor subtype in the pituitary, is also distributed over several brain areas related to emotional processing and has been implicated in the neurobiology of depressive disorders $[15,16]$.

Single nucleotide polymorphisms (SNPs) of the CRHRI gene have been associated with depressive disorders in adults with a history of childhood abuse [17-20], with the severity of depressive symptoms and suicide risk [21,22], and with the response to antidepressants [23]. Five CRHR1 polymorphisms (rs17689966, rs173365, rs7209436, rs110402, and rs242924) have been associated with depressive disorders, and the TAT haplotype in SNPs rs7209436, rs 110402, and rs242924 has been found with increased frequency in depressed patients compared with controls [24]. The presence of TAT haplotypes in the CRHR1 gene seems to play a role in the neurobiology of depressive disorders, although the direction of this influence remains unclear, since both protective effects $[17,19]$ and increased risk $[20,24]$ for the occurrence of depression have been described.

Studies assessing polymorphisms of the CRHR1 gene in PPD are scarce and their results are inconclusive. While two investigations failed to find associations between peripartum depression and CRHR1 polymorphisms [25,26], a third one found a positive association between the $G$ allele of the CRHR1 SNP rs242939 and depression during both pregnancy and postpartum, but the presence of the T allele of SNP rs242941 was associated only with postpartum depression [27]. In addition, few studies have investigated the associations between CRHR1 polymorphisms and the functioning of the HPA axis. SNPs of the CRHR1 gene were not associated with altered cortisol levels in depressed patients [28], but predicted increases in cortisol levels induced by the dexamethasone suppression test in healthy adults with a history of abuse during childhood [29]. The presence of TAT haplotypes has also been implicated in the deregulation of daily cortisol levels in abused children [30].

In this study we investigated whether variants of the CRHR1 gene were associated with alterations in the diurnal variation of cortisol levels and HPA axis responsiveness, measured through the cortisol awakening response (CAR), in a group of depressed and euthymic postpartum women who had been previously assessed in respect to HPA axis function [11]. The CAR is an acute episode of cortisol secretion that occurs around 30 minutes after awakening, when maximal concentrations of cortisol are observed [31]. It is a natural model of response to endogenous stress and is used as a measure of HPA axis responsiveness [32]. Considering the contradictory results regarding the role of TAT haplotypes in depressive disorders and the impact of this haplotype in HPA axis activity, we investigated whether genetic variations in the CRHR1 gene can explain the dysregulation of the HPA axis seen in the context of PPD as assessed by measures of HPA axis responsiveness (CAR) and diurnal variation in cortisol levels.

\section{Material and Methods}

\section{n Participants}

This study is part of the study "BRISA" (Brazilian Ribeirão Preto and São Luis Prenatal Cohort) [33]. As proposed in the original project, pregnant volunteers were invited to fill up questionnaires, 
Implications of Polymorphisms in the CRHR1 Gene on the Hypothalamic-Pituitary-Adrenal Axis Research Functioning in Postpartum Depression

respond to interviews, and provide blood samples for genetic analyses. In the postpartum period, the previously selected volunteers were also asked to collect saliva samples at home for later quantification of cortisol levels, as described elsewhere [11,34].

Data for the characterization of the sample were collected in three occasions: (1) between 22 and 25 weeks of pregnancy, when data were extracted from a complex database of the original study and blood samples for genetic analyses were collected; (2) on the day of delivery, using data from the medical-hospital records; and (3) in the postpartum period, when diagnostic interviews were made and saliva samples for cortisol measures were collected, as shown in Figure 1.

From the assessments performed during pregnancy in the original project [33], we included, in this study, the Center for Epidemiological Studies Depression scale (CES-D) $[35,36]$ and the Perceived Stress Scale (PSS-14) [37,38] to measure, respectively, the occurrence of depressive symptoms and the perception of stress by mothers during pregnancy.

Among the scales to be completed in the postpartum, we included the Epworth Sleepiness Scale (ESS) that assesses sleepiness during the day in adults $[39,40]$, since alterations in the sleep-wake cycle may affect the regulation of the HPA axis; the Edinburgh Postnatal Depression Scale (EPDS) [41,42], whose scores reflect the presence and intensity of depressive symptoms, and the clinical version of the Structured Clinical Interview for the DSM-IV (SCID-CV) $[43,44]$, which was applied to confirm or exclude the diagnosis of a major depressive episode (MDE).

Criteria and steps for sample composition: We included women whose children were born in the city of Ribeirão Preto, Brazil. Participants who used psychoactive substances (except for psychotropic medication for depression) and suffering from other medical conditions and mental disorders were not included in the study, except for anxiety disorders, which is a highly common comorbidity in depressive disorders [45].

To compose the sample for the present study, we invited women in their postpartum period that took part in the study for the validation of the EPDS applied by telephone [34] and later attended a face-to-face interview for the application of the SCID-CV, when 90 women were diagnosed with MDE and 109 were classified as euthymic. All the women assessed with the SCID-CV were invited to participate in the present study, except for 9 who were excluded ( 1 due to another medical condition and 8 due to the presence of other severe mental disorders) and 86 who refused to participate. Therefore, 104 postpartum women (51 depressed and 53 euthymic) were asked to provide saliva samples for cortisol analyses. However, 7 participants (5 depressed and 2 euthymic) failed to return the samples and 16 (9 depressed and 7 euthymic) returned insufficient samples for cortisol analyses. From the 81 volunteers with adequate saliva samples, 2 were excluded because they presented discrepant cortisol levels 12 hours after awakening and 1 was excluded because of the absence of genotyping. The final sample, therefore, consisted of 78 volunteers (41 euthymic and 37 depressed). As reported previously [11], there was no difference between the missing sample and the final sample regarding demographic, postnatal, and new-born characteristics or mental health during pregnancy or postpartum, except for the higher proportion of vaginal delivery among women who completed the study.

The study was approved by the Ethics Committee of the Ribeirão Preto Medical School University Hospital (process numbers 5169/2010 and 5560/2011). All volunteers were given detailed information concerning the methods and objectives of the study and provided their signed consent to participate.

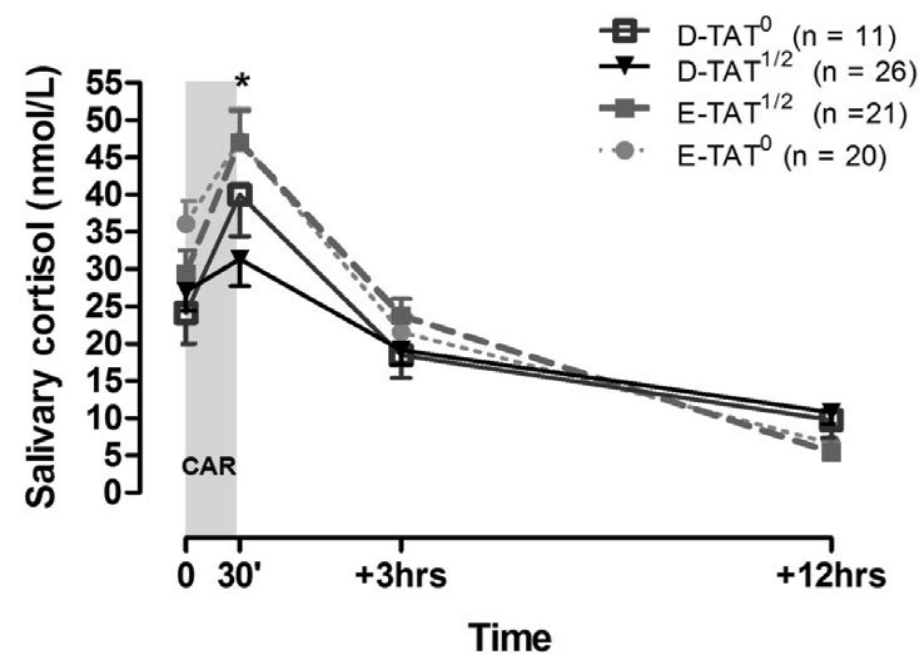

Figure 1: Sequence of experimental protocol. 
Cortisol samples quantification and measures of the HPA axis: As described elsewhere [11], cortisol samples were collected by each participant according to written instructions and using four cotton swabs (salivettes) labeled with the subject's name and date of collection. Saliva samples were all collected on the same day, in the following time points: upon awakening, while still in bed (T1); 30 minutes after awakening (T2); 3 hours after awakening (T3); and 12 hours after awakening (T4). On the day preceding the collection, participants were contacted by telephone in order to be reminded of the procedure, as well as to emphasize the instructions and the need to fill up a checklist with the procedures performed.

After the samples were collected, they were stored under refrigeration at the participants' houses until the research staff picked them up. Following the arrival at the laboratory, the samples were centrifuged at $3.000 \mathrm{rpm}$ for 10 minutes and stored at $-30^{\circ} \mathrm{C}$. Salivary cortisol levels were determined in duplicates by radioimmunoassay in $25 \mu \mathrm{l}$ saliva samples [46]. The assay sensitivity was of $60 \mathrm{ng} / \mathrm{dL}$. The intra- and interassay variation coefficients were respectively $2.1 \%$ and $9.3 \%$. Resulting values were expressed in nanomoles per liter $(\mathrm{nmol} / \mathrm{L})$ in order to facilitate the comparison of results with those of previous studies. The transformation from $\mathrm{ng} / \mathrm{dL}$ to $\mathrm{nmol} / \mathrm{L}$ was made by multiplying values in $\mathrm{ng} / \mathrm{dL}$ by 0.028 .

To verify the presence of CAR and confirm the reactivity of the HPA axis upon awakening, we calculated its relative increment (relative increment of cortisol concentrations upon awakening; CARi\%) [47]. According to the following formula: CARi $\%=\{[(\mathrm{T} 2-\mathrm{T} 1) /$ $\left.\mathrm{T} 1]^{*} 100\right\}$. A CARi $\geq 50 \%$ was the cutoff used to establish the presence of HPA reactivity [48].

DNA extraction: In the prenatal interview, 4 $\mathrm{ml}$ of peripheral venous blood were collected from each participant in two tubes containing EDTA for the extraction of genomic DNA. Immediately after collection, blood samples were centrifuged for the separation of cells, which were placed in properly labeled $2 \mathrm{ml}$ tubes that were stored at $-20^{\circ} \mathrm{C}$. Genomic DNA was then extracted using the FlexiGene DNA kit (Cat. No. 51106; Qiagen) according to the manufacturer's instructions. After the extraction of genomic DNA, polymorphism analyses were performed at the Multidisciplinary Laboratory for Molecular Biology in Neuroscience of the Ribeirão Preto
Medical School.

CRHR1 SNP genotyping: The three CRHR1 SNPs (rs7209436, rs110402, rs242924) were genotyped by allelic discrimination using TaqMan probes designed with the PrimerQuest tool (Integrated DNA Technologies, IDT) for each SNP, and probe specificity was analyzed with the OligoAnalyzer tool (IDT) in the genotyping platform 7500 Fast Real Time PCR system (Applied Biosystems, Foster City, California), as described elsewhere [17].

Polymerase chain reaction (PCR) was performed according to the following cycle conditions: denaturation ( 15 minutes) at $95^{\circ} \mathrm{C}$, followed by 35 cycles at $94^{\circ} \mathrm{C}$ for 30 seconds, $66^{\circ} \mathrm{C}$ for 30 seconds, and $72^{\circ} \mathrm{C}$ for 40 seconds, with a final extension step at $72^{\circ} \mathrm{C}$ for 15 minutes. Reactions were performed in a $10 \mathrm{X}$ reaction buffer (Invitrogen), $1.5 \mathrm{mM}$ of magnesium chloride, 50 ng of genomic DNA, 5 pmols of each primer, $0.3 \mathrm{mM}$ of each nitrogenous base (dATP, dCTP, dGTP, and dTTP) contained in $150 \mathrm{mmol} / \mathrm{L}$ of each primer and one unit of Taq polymerase (Invitrogen). Next, PCR products were separated by electrophoresis in $2.5 \%$ agarose gel (Sigma) supplemented with ethidium bromide $(0.03 \%)$ and later visualized through UV transillumination. Allelic discrimination analyses were processed with the TaqMan Genotyper software (Version 1.3 - Applied Biosystems).

Table 1 shows the frequency of haplotypes and alleles in the sample, comparing euthymic and depressive postpartum women. All SNPs in both samples were in Hardy-Weinberg equilibrium [49].

\section{Statistical Analysis}

Data were analyzed with the Statistical Package for the Social Sciences (SPSS), version 20.0. Continuous variables were analyzed through oneway analysis of variance (ANOVA), with means and standard deviations, whereas categorical variables were analyzed with Fisher's exact test.

Polymorphisms of the CHRHI gene were classified according to the presence (1 or 2 copies) or absence (0 copies) of the TAT haplotype, as suggested elsewhere [19,29,30].

Cortisol measures were log transformed for statistical analyses, but the figures present raw values. Log-transformed salivary cortisol levels were analyzed with a multivariate ANOVA (MANOVA) for repeated measures 
Implications of Polymorphisms in the CRHR1 Gene on the Hypothalamic-Pituitary-Adrenal Axis Research Functioning in Postpartum Depression

\begin{tabular}{|c|c|c|}
\hline & $\begin{array}{l}\text { Euthymic } \\
(\mathrm{n}=\mathrm{41})\end{array}$ & $\begin{array}{l}\text { Depressed } \\
(n=37)\end{array}$ \\
\hline \multicolumn{3}{|l|}{ rs7209436 } \\
\hline CC & 17 (41.5\%) & $10(27.0 \%)$ \\
\hline $\mathrm{TC}$ & 19 (46.3\%) & $19(51.4 \%)$ \\
\hline$\pi$ & $5(12.2 \%)$ & $8(21.6 \%)$ \\
\hline \multicolumn{3}{|l|}{ rs110402 } \\
\hline AA & $4(9.8 \%)$ & $8(21.6 \%)$ \\
\hline$A G$ & 17 (41.5\%) & $19(51.4 \%)$ \\
\hline GG & $20(48.8 \%)$ & $10(27.0 \%)$ \\
\hline \multicolumn{3}{|l|}{ rs242924 } \\
\hline GG & 20 (48.8\%) & $10(27.0 \%)$ \\
\hline TG & $15(36.6 \%)$ & $19(51.4 \%)$ \\
\hline$\pi$ & $6(14.6 \%)$ & $8(21.6 \%)$ \\
\hline \multicolumn{3}{|c|}{ TAT haplotype } \\
\hline 1 or 2 copies & 21 (51.2\%) & $26(70.3 \%)$ \\
\hline 0 copies & $20(48.8 \%)$ & 11 (29.7\%) \\
\hline
\end{tabular}

with two between-groups factors [diagnosis (depressed vs. euthymic) and genotype (CRHR1 polymorphisms with the presence vs. the absence of at least one copy of the TAT haplotype] and one intragroup factor [time (awakening, 30 minutes, 3 hours, and 12 hours after awakening)]. The degrees of freedom of the factors diagnosis, sample collection time, and genotype were corrected with Hotelling's Trace because of the bivariate nature of each independent variable. Post hoc comparisons were made using one-way ANOVA followed by Bonferroni correction. The paired-samples $t$-test was used for the comparison of mean cortisol levels upon awakening and 30 minutes later. Effect sizes were determined through Cohen's $d$ and classified as small $(d \leq 0.20)$, medium ( $d$ around 0.50$)$, or large $(d>0.80)$ [50]. As a secondary analysis, we used a multivariate analysis of covariance (MANCOVA) including the following clinical and demographic variables as covariates: PSS scores during pregnancy, ESS scores in the postpartum, age, education, marital status, body mass index (BMI), and use of contraceptive methods.

Spearman's correlation coefficient (rho) was used to test for correlations between CARi\% and the scores of the EPDS and PSS considering the presence or absence of at least one copy of the TAT haplotype. We also carried out a partial correlation analysis between EPDS and PSS total scores controlling for the effect of the CAR.

The level of statistical significance in the analyses was $p<0.05$.

\section{Results}

\section{- Clinical and demographic variables}

Table 2 shows the clinical and demographic characteristics of the participants. There were no differences between the groups in respect to the demographic, obstetric, or postnatal variables, neither in regard to new-born characteristics and collection periods. EPDS scores were higher in the group of depressed mothers, who also scored higher in the measures of mental health collected during pregnancy (CES-D and PSS) and in the occurrence of depressive episodes in the lifetime. Only two subjects were in treatment with antidepressants (selective serotonin reuptake inhibitors).

\section{- Assessment of the hypothalamus- pituitary-adrenal axis}

Saliva samples were collected approximately six months after delivery $($ mean $=169.6 \pm 60.5$ days). The repeated-measures model showed that, over the period of 12 hours, cortisol levels differed between groups depending on the presence of TAT haplotypes of the CRHR1 gene [time $\mathrm{x}$ diagnosis $\mathrm{x} C R H R 1$ interaction $\mathrm{F}(3.0$; $72.0)=3.38 ; p=0.023$ ] , as shown in Figure 2. The one-way ANOVA followed by Bonferroni test showed statistically significant differences between groups in samples collected 30 minutes after awakening $[\mathrm{F}(3.74)=5.03 ; p=0.003]$, with $\mathrm{D}-\mathrm{TAT}^{1 / 2}$ women presenting significantly lower cortisol levels than E-TAT ${ }^{1 / 2}(p=0.024$; $d=0.780)$ and $\mathrm{E}^{-\mathrm{TAT}^{0}}$ women $(p=0.003$; $d$ $=1.020)$, but with no significant differences 
Research Marcos Gonçalves de Rezende

\begin{tabular}{|c|c|c|c|c|c|}
\hline & $\begin{array}{l}\text { D-TAT } \\
(n=11)\end{array}$ & $\begin{array}{l}\text { D-TAT } \\
(n=26)\end{array}$ & $\begin{array}{l}\text { E-TAT } \\
(n=20)\end{array}$ & $\begin{array}{l}\text { E-TAT }^{1 / 2} \\
(n=21)\end{array}$ & $p$ \\
\hline \multicolumn{6}{|l|}{ Demographics } \\
\hline Age: mean (SD) & $25.4(5.9)$ & $28.8(4.9)$ & $27.9(6.1)$ & $27.4(4.7)$ & 0.350 \\
\hline Years of education: $\geq 9$ years (\%) & 72.7 & 84.6 & 85.0 & 57.1 & 0.127 \\
\hline Living with partner (\%) & 90.9 & 88.5 & 90.0 & 90.5 & 1.000 \\
\hline Ethnicity: White (\%) & 27.3 & 54.0 & 45.0 & 57.1 & 0.391 \\
\hline \multicolumn{6}{|l|}{ Delivery and postnatal features } \\
\hline Primiparous (\%) & 27.3 & 23.1 & 25.0 & 38.1 & 0.723 \\
\hline Gestational age in weeks: mean (SD) & $38.8(2.1)$ & $38.8(2.2)$ & $39.6(1.4)$ & $39.6(1.5)$ & 0.335 \\
\hline Vaginal delivery (\%) & 54.5 & 61.5 & 70.0 & 61.9 & 0.850 \\
\hline Breastfeeding (\%) & 81.8 & 96.2 & 90.0 & 85.7 & 0.452 \\
\hline Use of contraceptives (\%) & 81.8 & 72.0 & 65.0 & 52.4 & 0.370 \\
\hline Body mass index $\left(\mathrm{kg} / \mathrm{m}^{2}\right)$ : mean (SD) & 26.5 (3.6) & $27.6(4.5)$ & $27.3(4.7)$ & $27.4(4.5)$ & 0.921 \\
\hline \multicolumn{6}{|l|}{ Newborn features } \\
\hline Male (\%) & 45.5 & 42.3 & 50.0 & 52.4 & 0.925 \\
\hline 5-minute APGAR score: mean (SD) & $9.5(1.0)$ & $9.5(0.8)$ & $9.5(0.8)$ & $9.7(0.6)$ & 0.806 \\
\hline \multicolumn{6}{|l|}{ Mental health during pregnancy } \\
\hline Perceived Stress Scale: mean (SD) & $26.8(7.2)$ & $30.6(9.2)$ & $23.7(11.2)$ & $24.1(7.0)$ & $0.048^{*}$ \\
\hline Depression during pregnancy (\%) & 50.0 & 65.4 & 30.0 & 16.7 & $0.007^{*}$ \\
\hline \multicolumn{6}{|l|}{ Mental health in the postpartum } \\
\hline ESS: mean (SD) & $8.9(5.3)$ & $8.8(6.1)$ & $9.3(5.1)$ & $7.9(5.2)$ & 0.860 \\
\hline EPDS: mean (SD) & $15.7(4.6)$ & $16.8(5.7)$ & $7.4(4.8)$ & $3.5(3.1)$ & $<0.001 *$ \\
\hline Depressive episode in lifetime (\%) & 36.4 & 38.5 & 10.0 & 23.8 & 0.143 \\
\hline Current use of psychotropics (\%) & 9.1 & 3.8 & NA & NA & 0.373 \\
\hline \multicolumn{6}{|l|}{ Cortisol sample collection } \\
\hline Postpartum period in days: mean (SD) & $169.1(76.7)$ & $169.6(59.4)$ & $162.0(46.1)$ & $170(52.2)$ & 0.967 \\
\hline Time at awakening: mean (SD) & $7: 12(1: 32)$ & $7: 40(1: 38)$ & $6: 45(1: 27)$ & $7: 31(1: 20)$ & 0.251 \\
\hline \multicolumn{6}{|c|}{$\begin{array}{l}\text { D-TAT }^{0} \text { : depressed postpartum women without TAT copies; D-TAT } \\
\text { postpartum women without } \text { : depressed copies; E-TAT }{ }^{1 / 2} \text { : euthymic postpartum women with } 1 \text { or } 2 \text { TAT copies; SD: standard deviation; NA: not applicable } \\
\text { CES-D: Center for Epidemiological Studies Depression scale; ESS: Epworth Sleepiness Scale; EPDS: Edinburgh Postnatal Depression Scale; } \\
\text { *statistically significant difference }(p<0.05) \text {. }\end{array}$} \\
\hline
\end{tabular}

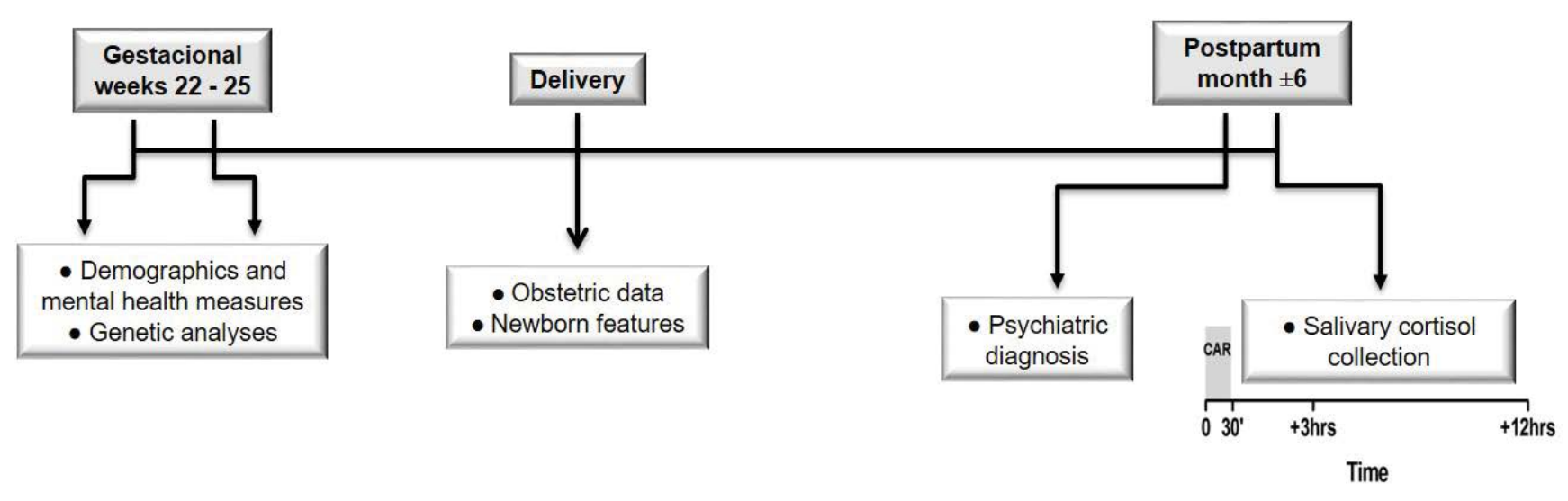

Figure 2: Cortisol awakening response in depressed postpartum women without TAT copies (D-TAT ${ }^{0}$ ) and with 1 or 2 copies (D-TAT $\left.{ }^{1 / 2}\right)$ and in euthymic postpartum women without TAT copies $\left(\mathrm{E}_{-} \mathrm{TAT}^{0}\right)$ and with 1 or 2 copies $\left(\mathrm{E}-\mathrm{TAT}^{1 / 2}\right)$ in the polymorphism of the CRHR1 gene.

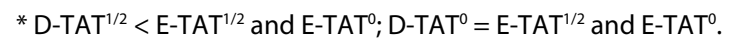

CAR: Cortisol awakening response (awakening $(0) \rightarrow 30 \mathrm{~min}$ ).

compared to D-TAT ${ }^{0}$ women $(p=0.427 ; d=$ $0.701)$. The cortisol levels of samples collected 30 minutes after awakening in $\mathrm{D}^{-\mathrm{TAT}^{0}}{ }^{0}$ subjects were not significantly different from those of

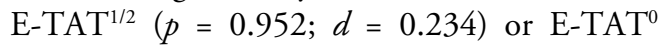
participants $(p=0.701 ; d=0.527)$. There were 
no statistically significant differences between cortisol levels at awakening and 3 and 12 hours later between groups.

The paired-samples $t$-test showed differences between the baseline levels of cortisol at awakening and 30 minutes later in ${\mathrm{E}-\mathrm{TAT}^{0}}^{0}(t$ $=-3.792 ; p=0.001 ; d=0.700), \mathrm{E}_{-T A T}{ }^{1 / 2}(t$ $=-5.763 ; p<0.001 ; d=1.000)$ and D-TAT ${ }^{0}$ groups $(t=-6.914 ; p<0.001 ; d=1.770)$, but not in $\mathrm{D}_{-T A T}{ }^{1 / 2}(t=-0.803 ; p=0.429 ; d=0.140)$.

The differences observed remained significant when covaried with age, education, marital status, PSS and ESS scores, BMI, and contraceptive treatment [time $\mathrm{x}$ diagnosis $\mathrm{x} C R H R 1$ interaction $\mathrm{F}(0.146 ; 58.0)=2.82 ; \mathrm{p}=0.047]$. Furthermore, the exclusion of participants with comorbid anxiety disorders and in treatment with antidepressants had no effects on the statistically significant differences observed.

Table 3 shows the distribution of the TAT haplotype in the two groups in relation to the presence (CARi $\geq 50 \%$ ) or absence (CARi < $50 \%)$ of cortisol awakening response. There was a significant difference between groups (Fisher's exact test, $\mathrm{p}=0.018$ ) resulting from a higher proportion of women without CAR (increase in cortisol levels below 50\%) among D-TAT ${ }^{1 / 2}$ subjects $(80.8 \%)$ compared to D-TAT ${ }^{0}(36.4 \%$; $p=0.018)$ and $\mathrm{E} \mathrm{TAT}^{1 / 2}$ subjects $(42.9 \% ; p=$ $0.014)$.

The presence or absence of CAR was not influenced by the method $\left(\chi^{2}=0.498 ; \mathrm{p}=0.480\right)$ or season $\left({ }^{2}=0.296 ; \mathrm{p}=0.580\right)$ of delivery.

The CARi\% was negatively correlated with depressive symptoms in the remote postpartum, as measured by the EPDS ( $\mathrm{n}=47$; rho $=-0.487$; $p=0.001$ ), and with the perception of stress during pregnancy, as measured by the PSS ( $\mathrm{n}$ = 44; rho $=-0.442 ; p=0.003$ ), in postpartum women with at least one copy of the TAT haplotype. However, in women with no TAT copies, there was no correlation between the CARi $\%$ and EPDS $(\mathrm{n}=31$; rho $=0.215 ; p=$ 0.246 ) or PSS ( $\mathrm{n}=28$; rho $=0.183 ; p=0.352$ ) scores. Figure 3 shows the correlations between the CARi\% and the EPDS and PSS scores.

There was also a significant positive correlation between PSS and EPDS total scores for both groups (at least one TAT copy: rho $=0.402, \mathrm{p}=$ 0.007; no TAT copies: rho $=0.517, \mathrm{p}=0.005$ ). However, when we carried out a partial analysis controlling for the CAR effects, the significance for the correlation among women with at least one TAT copy was lost $(r h o=0.214, p=0.167)$, which did not happen among women without TAT copies ( $\mathrm{rho}=0.514, \mathrm{p}=0.006)$.

\section{Discussion}

We investigated the association of a haplotype from three polymorphisms (rs7209436, rs 110402, and rs242924) of the gene that codes the CRH type 1 receptor with salivary cortisol levels, measured immediately upon awakening and throughout the day, in the remote postpartum of depressed and euthymic women. We found no statistically significant differences in cortisol baseline levels or its variations over the day, but the presence of at least one copy of the TAT haplotype was related with HPA axis responsiveness in depressed women. In women with no TAT copies, the cortisol response of depressed and euthymic women at 30 minutes after awakening was similar, but depressed women with at least one TAT copy had significantly lower cortisol levels compared with euthymic women with one or two TAT copies.

Previous studies have shown that variations in SNPs of the CRHR1 gene were associated with abnormalities in the daily cortisol levels of abused children [30] and in the cortisol response to the dexamethasone/CRH test in adults who were abused in childhood, with the strongest cortisol responses observed in GG homozygous individuals [29]. However, to our knowledge, this is the first study showing an association between the presence of the TAT haplotype of the CRHRI gene and the attenuation of the cortisol awakening response (CAR) in postpartum depression.

\begin{tabular}{|c|c|c|c|c|c|}
\hline & $\begin{array}{l}\text { D-TAT }^{0} \\
\text { n (\%) }\end{array}$ & $\begin{array}{l}\text { D-TAT }{ }^{1 / 2} \\
\text { n (\%) }\end{array}$ & $\begin{array}{l}\text { E-TAT }^{0} \\
\text { n (\%) }\end{array}$ & $\begin{array}{l}\text { E-TAT }^{1 / 2} \\
\text { n (\%) }\end{array}$ & $\begin{array}{l}\text { Total } \\
\text { n (\%) }\end{array}$ \\
\hline CARi $\geq 50 \%$ & 7 (63.6) & $5(19.2)$ & 7 (35.0) & $12(57.1)$ & 31 (39.7) \\
\hline CARi $<50 \%$ & $4(36.4)$ & $21(80.8)$ & $13(65.0)$ & $9(42.9)$ & $47(60.3)$ \\
\hline Total & $11(100.0)$ & $26(100.0)$ & $20(100.0)$ & $21(100.0)$ & $78(100.0)$ \\
\hline
\end{tabular}

D-TAT: depressed postpartum women without TAT copies; D-TAT ${ }^{1 / 2}$ : depressed postpartum women with 1 or 2 TAT copies; E-TAT : euthymic postpartum women without TAT copies; E-TAT ${ }^{1 / 2}$ : euthymic postpartum women with 1 or 2 TAT copies; CARi\%: relative increment in cortisol concentrations 30 minutes after awakening. 
Implications of Polymorphisms in the CRHR1 Gene on the Hypothalamic-Pituitary-Adrenal Axis Research Functioning in Postpartum Depression
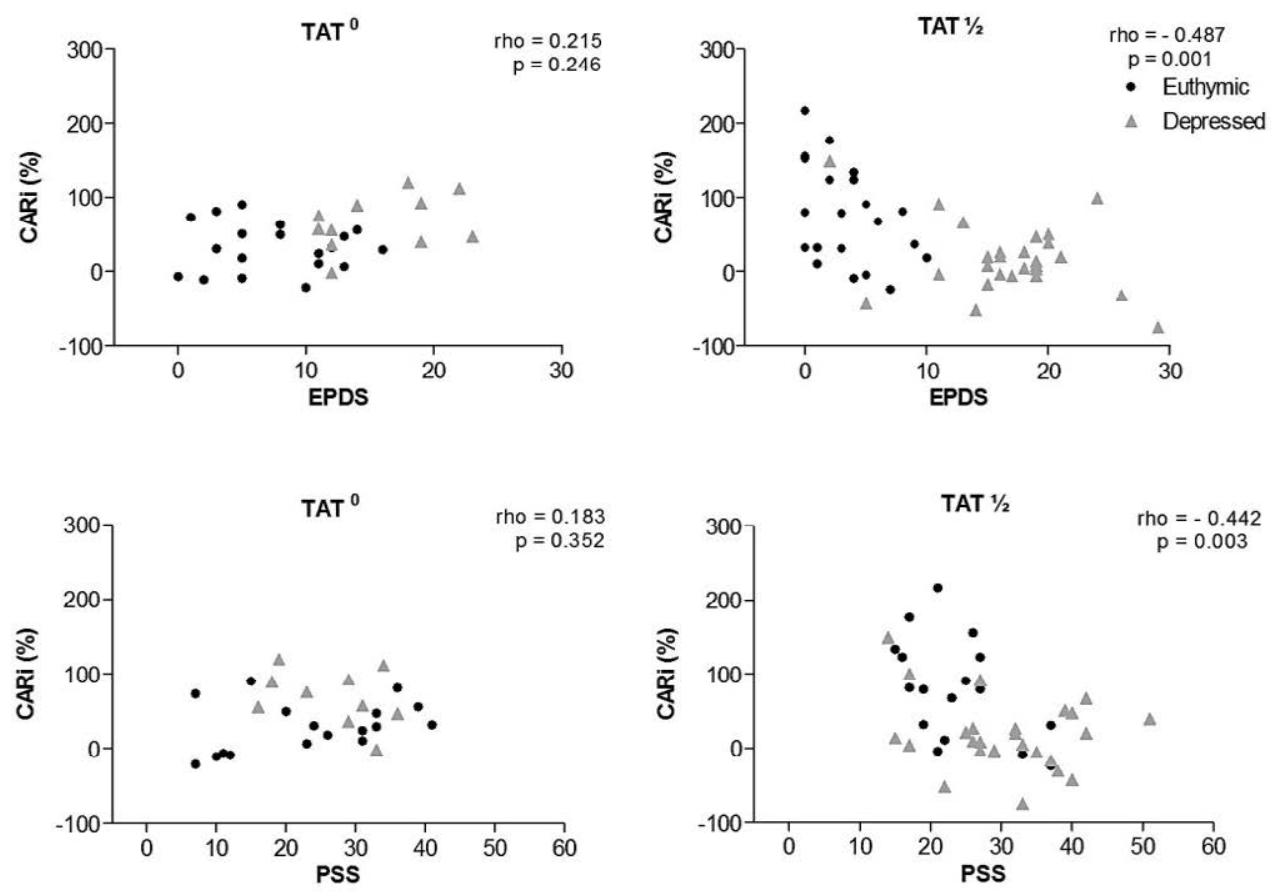

Figure 1: Correlations between the relative increment in cortisol concentrations at awakening (CARi\%) and the Edinburgh Postpartum Depression Scale (EPDS) and Perceived Stress Scale (PSS) scores, in postpartum women without (TAT0) and with 1 or 2 (TAT1/2) TAT copies in the CRHR1 gene.

We also found that, in women with at least one copy of the TAT haplotype, the CAR assessed six months after delivery correlated negatively with the severity of depressive complaints evaluated at the same time of the salivary cortisol measurements in the postpartum, but also with the perception of stressful events registered during pregnancy; which was not observed in women without TAT copies. Interestingly, in the partial correlation analysis controlling for CAR effects, the positive correlation between measures of perceived stress during pregnancy and postpartum depressive symptoms was lost only in carriers of the TAT haplotype, which reinforces the view that HPA axis function plays a role in the complex interaction between stressful events and depressive disorders.

The occurrence of stressors during the lifespan has been described as an important risk factor for depressive disorders [51,52], including peripartum depressive episodes [53,54]. The CRHR1 polymorphisms seem to modulate the sensitivity to stress, probably through their role in the regulation of HPA axis function, increasing the risk of depression [29,55]; but, unfortunately, our data do not allow us to establish causal relationships. Nonetheless, considering the amount and complexity of biological and psychological events inherent to the peripartum period, it is tempting to speculate that women carrying TAT copies may have an increased vulnerability to environmental stressors [20], as measured by the perception of the occurrence of stressful events during pregnancy, which, in turn, could increase the risk of depressive symptoms during the postpartum.

It is important to note that the pattern of attenuated CAR that we observed in depressed postpartum women is similar to that seen in atypical depression [56] and chronic stress conditions such as fatigue and exhaustion [57]. A possible explanation for this pattern of decreased CAR in PPD could be related to the typical demands of the puerperium, a period in which the care to the newborn and other specific environmental stressors may lead to chronic fatigue and exhaustion. Moreover, during pregnancy, physiological alterations in the normal functioning of the HPA axis may persist as a risk factor in women with genetic vulnerability to depression $[7,58]$. However, while all women experience such extreme changes in hormonal levels after delivery, only some develop PPD, which reinforces the hypothesis of an individual sensitivity to the biological and/or psychological changes of the postpartum period [6].

Our results corroborate earlier evidence from studies involving adults with two copies of the 
TAT haplotype that presented an increased risk of depressive symptoms secondary to a history of childhood abuse [20,24]. Conversely, two studies described a protective effect of the presence of TAT copies against depression in individuals with a history of abuse $[17,19]$. Many factors could explain these discrepancies, such as different types of traumatic events and age of exposure, variability in the severity and comorbidity of mental disorders, interference of other variables such as aminergic systems and possible associations between CRHR1 SNPs and SNPs of other genes $[59,60]$.

It is important to note that, although in silico analyses suggest that SNPs within the CRHR1 locus may have an impact on the function of the gene, there is no evidence to date that these polymorphisms can actually change the CRHRI gene function [15]. Furthermore, the complexity of epigenetic effects continues to be an obstacle for the study of the impact of polymorphisms on different diseases, and the role of CRHR1 polymorphisms seems to depend on a number of variables. For instance, the A allele of SNP rs 110402 has been associated with decreased cortisol response in the dexamethasone and $\mathrm{CRH}$ suppression test in men with a history of childhood trauma, whereas an increase in cortisol response to these tests was found in women with the A allele who suffered childhood abuse. On the other hand, there was no influence of gender in carriers of the A allele with no history of trauma [18]. Ethnicity seems to be another factor involved in the interaction between polymorphic copies and stress response. In African-American women who went through adverse experiences in childhood, the TAT haplotype reduced the chances of the occurrence of depressive disorders, whereas in women who did not go through adversity the presence of the TAT haplotype increased the risk of depressive disorders. In the same study, no association was observed in women of European descent or in men of African or European descent [61].

A limitation of our study refers to the sample size, which hindered the use of more robust analyses such as predictive or mixed models. Another restraint was the absence of cortisol samples collected at midnight, since this measure would allow the assessment of the circadian rhythm, another parameter of integrity of the HPA axis and that is commonly lost in disease and stress conditions [62]. Also, the scale used in this study to assess sleep, the Epworth Sleepiness Scale, may not be the most appropriate tool for assessing the quality of nocturnal sleep [63]. In turn, we were able to study patients with the diagnosis of major depressive disorder confirmed by a structured clinical interview and free of medication, except for two patients, who were under antidepressants. Strength of our study is the use of a reliable measure of HPA axis activity, considering its physiological dynamics.

\section{Conclusion}

In conclusion, we found that the presence of at least one copy of the TAT haplotype in three polymorphisms of the CRHRI gene was associated with decreased responsiveness of the HPA axis in depressed postpartum women. Our findings support the view that, in addition to environmental factors, genetic factors such as SNPs in genes of the CRH system, which plays an important role in stress responses and regulates the HPA axis, can be involved in the physiopathology of postpartum depression. The present findings and those from previous investigations on the role of gene polymorphisms in the pathophysiology of mental disorders highlight the need for a more personalized medicine, based on genetic testing for pharmacogenetics and disease management.

\section{Acknowledgements \\ The authors are indebted to Stella Felipe Freitas by technical assistance in extraction of genomic DNA and polymorphism analyses. \\ MG Rezende, MA Barbieri, $H$ Bettiol, RC Cavalli, $M$ Castro and CM Del-Ben are recipients of fellowships from CNPq (National Counsel of Technological and Scientific Development).}

This research was funded by São Paulo Research Foundation (Fundação de Amparo à Pesquisa do Estado de Sáo Paulo, FAPESP - grant numbers 2008/53593-0 and 2010/09066-0). This organization has no involvement in the research, beyond the supply of funding.

\section{Conflict of Interest}

The authors declare no conflict of interest.

\section{Contributors}

CMD-B, CG-L and MGR contribute to the conception and design of the study. MGR and FPF collected the data. MGR, CMD-B, FPF and $\mathrm{MC}$ analyzed and interpreted the data. 
Implications of Polymorphisms in the CRHR1 Gene on the Hypothalamic-Pituitary-Adrenal Axis Research Functioning in Postpartum Depression

MGR wrote the first draft of the manuscript. MGR, MAB, HB, RCC, CMD-B, FPF, HAF and $\mathrm{MC}$ contributed substantially to the revision of the manuscript. All authors participated in the preparation of the article, and all approved the final manuscript before submission.

\section{References}

1. O'Hara MW, Wisner KL. Perinatal mental illness: definition, description and aetiology. Best Pract. Res. Clin. Obstet. Gynaecol 28(1), 3-12 (2014).

2. Verbeek T, Bockting $\mathrm{CLH}$, van Pampus MG, et al. Postpartum depression predicts offspring mental health problems in adolescence independently of parental lifetime psychopathology. J. Affect. Disord 136(3), 948954 (2012).

3. Letourneau NL, Dennis C-L, Benzies K, et al. Postpartum depression is a family affair: addressing the impact on mothers, fathers, and children. Issues. Ment. Health. Nurs 33(7), 445-457 (2012).

4. Evagorou O, Arvaniti A, Samakouri M. CrossCultural Approach of Postpartum Depression: Manifestation, Practices Applied, Risk Factors and Therapeutic Interventions. Psychiatr Q (2015).

5. Brummelte S, Galea LA. Depression during pregnancy and postpartum: contribution of stress and ovarian hormones. Prog. Neuropsychopharmacol. Biol. Psychiatry 34(5), 766-776 (2010)

6. Bloch M. Effects of Gonadal Steroids in Women With a History of Postpartum Depression. Am. J. Psychiatry 157(6), 924-930 (2000).

7. Kammerer M, Taylor A, Glover V. The HPA axis and perinatal depression: a hypothesis. Arch. Womens. Ment. Heal 9(4), 187-196 (2006).

8. Jolley SN, Elmore S, Barnard KE, et al. Dysregulation of the hypothalamic-pituitaryadrenal axis in postpartum depression. Biol. Res. Nurs 8(3), 210-222 (2007).

9. Saleh el S, El-Bahei W, Del El-Hadidy MA, et al. Predictors of postpartum depression in a sample of Egyptian women. Neuropsychiatr. Dis. Treat 9(1), 15-24 (2013).

10. Taylor A, Glover V, Marks M, et al. Diurna pattern of cortisol output in postnatal depression. Psychoneuroendocrinology 34(8), 1184-1188 (2009).

11. De Rezende MG, Garcia-Leal C, De Figueiredo $\mathrm{FP}$, et al. Altered functioning of the HPA axis in depressed postpartum women. J. Affect. Disord 193 (2016).

12. Smith SM, Vale WW. The role of the hypothalamic-pituitary-adrenal axis in neuroendocrine responses to stress. Dialogues. Clin. Neurosci 8(4), 383-395 (2006).

13. Kinlein SA, Wilson CD, Karatsoreos IN Dysregulated hypothalamic-pituitary-adrenal axis function contributes to altered endocrine and neurobehavioral responses to acute stress. Front. Psychiatry 6(1), 31 (2015).

14. Gelman PL, Flores-Ramos M, López-Martínez $M$, et al. Hypothalamic-pituitary-adrenal axis function during perinatal depression. Neurosci. Bull 31(3), 338-350 (2015).

15. Binder EB, Nemeroff CB. The CRF system, stress, depression and anxiety-insights from human genetic studies. Mol. Psychiatry 15(6), 574-88 (2010).

16. Waters RP, Rivalan M, Bangasser DA, et al. Evidence for the role of corticotropinreleasing factor in major depressive disorder. Neurosci. Biobehav. Rev 58(1), 63-78 (2015).

17. Bradley RG, Binder EB, Epstein MP, et al. Influence of child abuse on adult depression: moderation by the corticotropin-releasing hormone receptor gene. Arch. Gen. Psychiatry 65(2), 190-200 (2008).

18. Heim C, Bradley B, Mletzko TC, et al. Effect of Childhood Trauma on Adult Depression and Neuroendocrine Function: Sex-Specific Moderation by CRH Receptor 1 Gene. Front. Behav. Neurosci 3(1), 41 (2009).

19. Polanczyk G, Caspi A, Williams B, et al. Protective effect of CRHR1 gene variants on the development of adult depression following childhood maltreatment: replication and extension. Arch. Gen. Psychiatry 66(9), 978-985 (2009).

20. Laucht M, Treutlein J, Blomeyer D, et al. Interactive effects of corticotropin-releasing hormone receptor 1 gene and childhood adversity on depressive symptoms in young adults: findings from a longitudinal study. Eur. Neuropsychopharmacol 23(5), 358-367 (2013).

21. Wasserman $D$, Sokolowski $M$, Rozanov $V$, et al. The CRHR1 gene: a marker for suicidality in depressed males exposed to low stress. Genes. Brain. Behav 7(1), 14-19 (2008).

22. Wasserman D, Wasserman J, Rozanov V, et al. Depression in suicidal males: genetic risk variants in the CRHR1 gene. Genes. Brain. Behav 8(1), $72-79$ (2009).

23. Liu Z, Zhu F, Wang G, et al. Association study of corticotropin-releasing hormone receptor 1 gene polymorphisms and antidepressant response in major depressive disorders. Neurosci. Lett 414(2), 155-158 (2007).

24. Ching-Lopez A, Cervilla J, Rivera M, et al. Epidemiological support for genetic variability at hypothalamic-pituitary-adrenal axis and serotonergic system as risk factors for major depression. Neuropsychiatr. Dis. Treat 11(1), 2743-2754 (2015).
25. Schneider M, Engel A, Fasching PA, et al. Genetic variants in the genes of the stress hormone signalling pathway and depressive symptoms during and after pregnancy. Biomed. Res. Int 2014, 469278 (2014).

26. Tan EC, Chua TE, Lee TM, et al. Case-control study of glucocorticoid receptor and corticotrophin-releasing hormone receptor gene variants and risk of perinatal depression. BMC. Pregnancy. Childbirth 15(1), 283 (2015).

27. Engineer N, Darwin L, Nishigandh D, et al. Association of glucocorticoid and type 1 corticotropin-releasing hormone receptors gene variants and risk for depression during pregnancy and post-partum. J. Psychiatr. Res 47(9), 1166-1173 (2013).

28. Schatzberg AF, Keller J, Tennakoon L, et al. HPA axis genetic variation, cortisol and psychosis in major depression. Mol. Psychiatry 19(2), 220-227 (2014).

29. Tyrka AR, Price LH, Gelernter J, et al. Interaction of childhood maltreatment with the corticotropin-releasing hormone receptor gene: effects on hypothalamic-pituitaryadrenal axis reactivity. Biol. Psychiatry 66(7), 681-685 (2009).

30. Cicchetti D, Rogosch FA, Oshri A. Interactive effects of corticotropin releasing hormone receptor 1 , serotonin transporter linked polymorphic region, and child maltreatment on diurnal cortisol regulation and internalizing symptomatology. Dev. Psychopathol 23(4), 1125-1138 (2011).

31. Wilhelm I, Born J, Kudielka BM, et al. Is the cortisol awakening rise a response to awakening? Psychoneuroendocrinology 32(4), 358-366 (2007)

32. Duan H, Yuan Y, Zhang L, et al. Chronic stress exposure decreases the cortisol awakening response in healthy young men. Stress 16(6), 630-637 (2013).

33. da Silva AAM, Simões VMF, Barbieri MA, et al. A protocol to identify non-classical risk factors for preterm births: the Brazilian Ribeirão Preto and São Luís prenatal cohort (BRISA). Reprod. Health 11(1), 79 (2014).

34. Figueiredo FP de, Parada AP, Cardoso VC, et al. Postpartum depression screening by telephone: a good alternative for public health and research. Arch. Womens. Ment. Health 18(3), 547-553 (2015).

35. Silveira D, Jorge MR. Psychometric properties of the epidemiologic screening scale for depression (CES-D) in clinical and non-clinical populations of adolescents and young adults. Psiq. Clin 25(1), 251-261 (1998).

36. Weissman MM, Sholomskas D, Pottenger M, 
et al. Assessing depressive symptoms in five psychiatric populations: a validation study. Am. J. Epidemiol 106(3), 203-214 (1977).

37. Cohen S, Kamarck T, Mermelstein R. A global measure of perceived stress. J. Heal. Soc. Behav 24(4), 385-396 (1983).

38. Luft CD, Sanches Sde O, Mazo GZ, et al. Brazilian version of the Perceived Stress Scale: translation and validation for the elderly. Rev. Saude. Publica 41(4), 606-615 (2007).

39. Bertolazi AN, Fagondes SC, Hoff LS, et al. Portuguese-language version of the Epworth sleepiness scale: validation for use in Brazil. J. Bras. Pneumol 35(9), 877-883 (2009).

40. Johns MW. A new method for measuring daytime sleepiness: the Epworth sleepiness scale. Sleep 14(6), 540-545 (1991).

41. Cox JL, Holden JM, Sagovsky R. Detection of postnatal depression. Development of the 10-item Edinburgh Postnatal Depression Scale. Br. J. Psychiatry 150(1), 782-786 (1987).

42. Santos IS, Matijasevich A, Tavares BF, et al. Validation of the Edinburgh Postnatal Depression Scale (EPDS) in a sample of mothers from the 2004 Pelotas Birth Cohort Study. Cad. Saude. Publica 23(11), 25772588 (2007).

43. First MB, Spitzer RL, Gibbon $M$, et al. Structured Clinical Interview for DSM-IV Axis I Disorders, Clinician Version (SCID-CV), for DSMIV. Am. Psychiatr. Press Inc Washingt. DC London Engl (1997).

44. Del-Ben CM, Vilela JAA, Crippa JAS, et al. Reliability of the Structured Clinical Interview for DSM-IV - Clinical Version translated into Portuguese. Rev. Bras. Psiquiatr 23(3), 156-159 (2001).

45. Halbreich U, Kahn LS. Atypical depression, somatic depression and anxious depression in women: are they gender-preferred phenotypes? J. Affect. Disord 102(1-3), 245-
258 (2007).

46. Castro M, Moreira AC. Análise crítica do cortisol salivar na avaliação do eixo hipotálamo-hipófise-adrenal. Arq. Bras. Endocrinol. Metabol 47(4), 358-367 (2003).

47. Clow A, Thorn L, Evans P, et al. The awakening cortisol response: methodological issues and significance. Stress 7(1), 29-37 (2004).

48. Pruessner JC, Wolf OT, Hellhammer DH, et al. Free cortisol levels after awakening: a reliable biological marker for the assessment of adrenocortical activity. Life. Sci 61(26), 2539-2549 (1997).

49. Rodriguez S, Gaunt TR, Day INM. Hardy-Weinberg Equilibrium Testing of Biological Ascertainment for Mendelian Randomization Studies. Am. J. Epidemiol 169(4), 505-514 (2009).

50. Cohen J. Statistical power analysis for the behavioral sciences. 2nd ed. Lawrence Erlbaum Associates, Hillsdale, NJ, USA (1998).

51. Bifulco A, Bernazzani O, Moran PM, et al. Lifetime stressors and recurrent depression: preliminary findings of the Adult Life Phase Interview (ALPHI). Soc. Psychiatry. Psychiatr. Epidemiol 35(6), 264-275 (2000).

52. Stein GL, Gonzalez LM, Huq N. Cultural stressors and the hopelessness model of depressive symptoms in Latino adolescents. J. Youth. Adolesc 41(10), 13391349 (2012).

53. Bunevicius R, Kusminskas L, Bunevicius A, et al. Psychosocial risk factors for depression during pregnancy. Acta. Obstet. Gynecol. Scand 88(5), 599-605 (2009).

54. Stone SL, Diop H, Declercq E, et al. Stressful events during pregnancy and postpartum depressive symptoms. J. Womens. Health (Larchmt) 24(5), 384-393 (2015).

55. Gillespie CF, Phifer J, Bradley B, et al. Risk and resilience: genetic and environmental influences on development of the stress response. Depress. Anxiety 26(11), 984-992 (2009).

56. Gold PW, Chrousos GP. Organization of the stress system and its dysregulation in melancholic and atypical depression: high vs low CRH/NE states. Mol. Psychiatry 7(3), 254-275 (2002).

57. Chida Y, Steptoe A. Cortisol awakening response and psychosocial factors: a systematic review and meta-analysis. Biol. Psychol 80(3), 265-278 (2009).

58. Glynn LM, Davis EP, Sandman CA. New insights into the role of perinatal HPA-axis dysregulation in postpartum depression. Neuropeptides 47(6), 363-370 (2013).

59. Pagliaccio D, Luby JL, Bogdan R, et al. Stress-system genes and life stress predict cortisol levels and amygdala and hippocampal volumes in children. Neuropsychopharmacology 39(5), 12451253 (2014).

60. Pagliaccio D, Luby JL, Bogdan R, et al. HPA axis genetic variation, pubertal status, and sex interact to predict amygdala and hippocampus responses to negative emotional faces in school-age children. Neuroimage 109(1), 1-11 (2015).

61. Kranzler HR, Feinn R, Nelson EC, et al. A CRHR1 haplotype moderates the effect of adverse childhood experiences on lifetime risk of major depressive episode in AfricanAmerican women. Am. J. Med. Genet. B. Neuropsychiatr. Genet 156B(8), 960-968 (2011).

62. Castro M, Elias PC, Quidute AR, et al. Outpatient screening for Cushing's syndrome: the sensitivity of the combination of circadian rhythm and overnight dexamethasone suppression salivary cortisol tests. J. Clin. Endocrinol. Metab 84(3), 878-882 (1999).

63. Sil A, Barr G. Assessment of predictive ability of Epworth scoring in screening of patients with sleep apnoea. J. Laryngol. Otol 126(4), 372-379 (2012). 